\title{
Direct Measurement of Intratracheal Pressure in Pediatric Respiratory Monitoring
}

\author{
SOREN SONDERGAARD, SIGURBERGUR KARASON, ANGELA HANSON, KRISTER NILSSON, \\ SVANTE HOJER, STEFAN LUNDIN, AND OLA STENQVIST
}

Department of Anaesthesia and Intensive Care, Sahlgrenska University Hospital, 41345 Göteborg [S.S., S.K., S.L., O.S.]; Department of Paediatric Anaesthesia and Intensive Care, The Queen Silvia Children's Hospital, 41685 Göteborg [A.H., K.N.]; and Samba Sensors AB, Första Långgatan 26, 41328 Göteborg, Sweden [S.H.]

\begin{abstract}
ABST
We describe a method based on a Fabry-Perot interferometer
at the tip of an optic fiber with a diameter of $0.25 \mathrm{~mm}$ for direct
measurement of tracheal pressure in pediatric respiratory moni-
toring. The response time of the pressure transducer and its
influence on the resistance of pediatric endotracheal tubes (in-
ternal diameter, 2.5 to 5 mm) during constant and dynamic flow
at different ventilator settings in a lung model were measured.
The transducer was positioned at -1.5 (inside), 0 , and $+1.5 \mathrm{~cm}$
(outside) relative to the tip of the endotracheal tube and com-
pared with a reference pressure inside the trachea. The clinical
application of the transducer was tested in five pediatric patients.
The response time of the transducer was 1.3 ms. The influence of
the fiberoptic transducer on tube resistance was negligible during
constant flow in inspiratory and expiratory directions for all
endotracheal tubes tested. There was no difference in pressure
measurements with the transducer positioned at or 1.5 cm below
or above the tip of the endotracheal tube during dynamic mea-
surements. During clinical circumstances insertion of the fiber-
\end{abstract}
optic transducer was easy, recordings were stable, and the safety of the patient was not jeopardized. The fiberoptic transducer provided a reliable and promising way of monitoring tracheal pressure in intubated pediatric patients. The presence of the probe did not interfere with either pressure-flow relationship or patient care and safety. The technique is proposed for monitoring of respiratory mechanics and calculation of changes in tube resistance caused by kinking and secretions. (Pediatr Res 51: 339-345, 2002)

ETT, endotracheal tube
ID, inner diameter
OD, outer diameter
FOPT, fiberoptic pressure transducer
P/V, pressure/volume
PEEP, positive end-expiratory pressure

Respiratory monitoring in pediatric intensive care is currently represented by proximal $\mathrm{P} / \mathrm{V}$ loops obtained in ventilator software or intensive care monitors using flowmeters placed near the connection between the ventilator system and ETT. This is obviously insufficient as information gained from such P/V loops mainly stems from ETT resistance and performance of ventilator valves. We have previously demonstrated that monitoring respiratory mechanics by direct measurement of tracheal pressure offers considerable advantages compared with monitoring based on either measurements obtained proximal to the tube or tracheal

Received April 17, 2001; accepted September 12, 2001

Correspondence and reprint requests: Soren Sondergaard, M.D., Department of Anaesthesia and Intensive Care, Sahlgrenska University Hospital, 41345 Göteborg, Sweden; e-mail: soren.sondergaard@swipnet.se

Supported by Göteborg Medical Society, AGA Medical Research Fund, and the Medical Faculty of Göteborg University (LUA no. A02913). pressures calculated by subtracting pressure needed to overcome flow-dependent tube resistance. In the adult setting tracheal pressure measurement is accomplished by introducing an air- or liquid-filled catheter into the ETT and connecting it to a conventional pressure transducer (1). In the pediatric setting it has generally been held to be impossible to use endotracheal catheters for continuous pressure measurement owing to the encroachment on cross-sectional area of the narrow pediatric tubes (2). Instead hydrodynamic models of varying complexity have been proposed for the calculation of tracheal pressure, i.e. the pressure fall across the ETT because of its resistance, based on measurements above the tube. Guttmann et al. (2) proposed an equation of the pressure fall by combining linear and quadratic pressureflow dependency and inertance relating to volume acceleration. The equation makes use of two inspiratory and two expiratory constants calculated in a bench model for each 
ETT of specified length, curvature, and diameter. Apart from the inertance component, it thus is similar to their method of calculating the pressure fall in the adult setting (3). Jarreau et al. (4) presented another approach to indirect measurement by dividing the total pressure drop into a fraction owing to loss of kinetic energy at entry and exit of tube, and a fraction owing to viscous pressure drop. The kinetic energy loss may be approximated by various equations (5), but its actual value is best estimated in the actual setting by subtracting the viscous pressure from the total pressure drop. The viscous pressure drop can be estimated by the Ito equation $(6,7)$ for laminar flows or by the Blasius equation (8) for turbulent flows. The Ito equation-besides flow-comprehensively takes tube length, curvature, and diameter as well as density and viscosity of the gas mixture into account. However, it is still uncertain whether test bench measurements may be safely applied in a clinical setting. Loring et al. (9) noted that changes in the position or angulation of the distal ETT could cause several-fold changes in effective resistance and concluded: "These factors make it difficult, if not impossible, to estimate ETT resistance reliably." Also, Sly et al. (10) seriously cautioned against the use of constants derived from in vitro experiments. Still, no methods of direct measurement of tracheal pressures in the pediatric clinical setting have been proposed or evaluated. Recently a fiberoptic system of very small dimensions for medical pressure measurements has become available. The fiber may be introduced into the ETT, and it is the aim of this paper to investigate the characteristics of this system and its feasibility for respiratory monitoring in pediatric intensive care and compare it with methods of calculating the tracheal pressure $(2,7)$.

\section{METHODS}

\section{Monitors, Measurements, and Data Acquisition}

The FOPT used for tracheal pressure measurement consists of a silicon sensor chip of $0.42 \mathrm{~mm}$ OD micromachined in silicon and attached to an optical fiber $0.25 \mathrm{~mm}$ OD (Samba Sensors AB, Göteborg, Sweden). It is a novel pressure sensor using a microcavity for sensing of the pressure. It is based on the interferometric principle (FabryPerot), which states that the deflection of the microcavity membrane by pressure results in a change in the reflected light intensity when the interference conditions inside the cavity are modified (11). Design variables can be changed to cover different pressure ranges. The cavity is evacuated, and the temperature drift is $0.05 \% /{ }^{\circ} \mathrm{C}$ in the range $20-45^{\circ} \mathrm{C}$. Spirometry signals were measured with Datex-Ohmeda multimodular monitor AS/3 (Datex-Ohmeda Ltd., Helsinki, Finland). Other pressure measurements were made with standard transducers for intravascular pressure (pvb medizintechnik, Kirchseeon, Germany). All signals were sampled via analog-to-digital converter (DT9804, Data Translations, Marlboro, MA, U.S.A.) to a TestPoint application (Capital Equipment Corporation, Billerica, MA, U.S.A.). The system is presented in Figure 1.

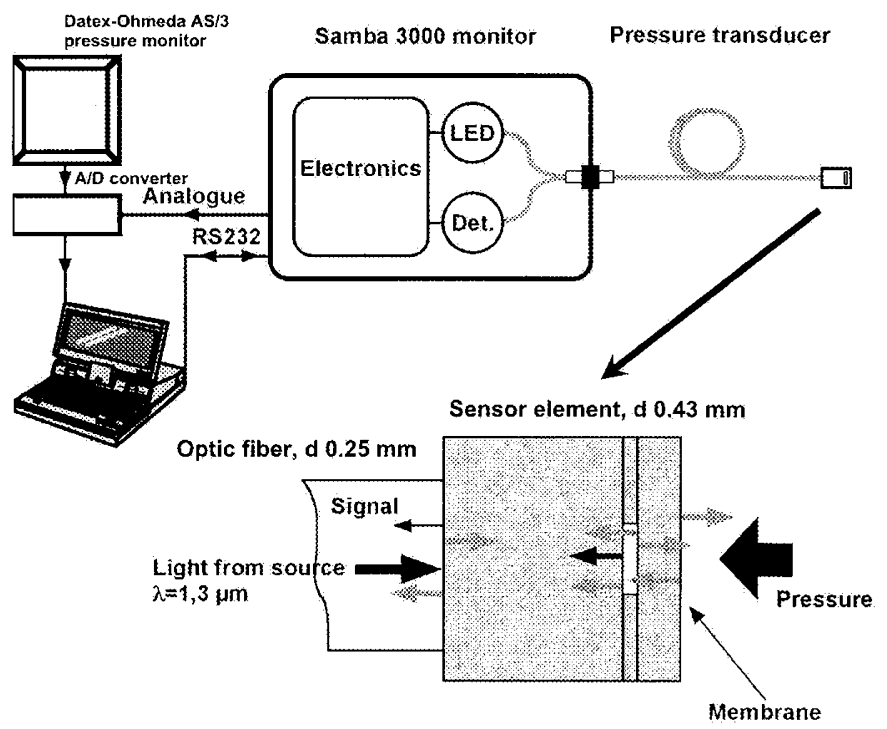

Figure 1. Samba monitor system with the FOPT enlarged, Datex A/S 3 monitor, analog-to-digital (A/D) converter and personal computer for data collection and controlling Samba monitor. LED, light-emitting diode, Det, optical detector.

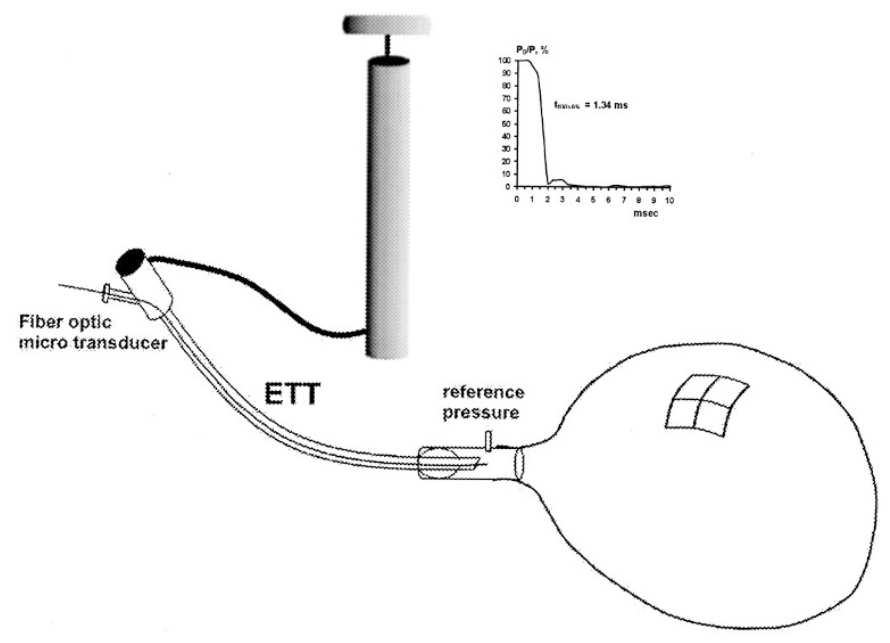

Figure 2. Measurement of response time of fiberoptic microsensor compared with reference pressure. The balloon was inflated to a pressure of $60-80 \mathrm{~cm}$ $\mathrm{H}_{2} \mathrm{O}$ and burst by a flame. Pressures were recorded at $3000 \mathrm{~Hz}$.

\section{Experimental and Clinical Testing}

Response time. A balloon was attached to a plastic trachea of $9 \mathrm{~mm}$ ID with a side hole for reference pressure measurement. The trachea was intubated with an ETT no. 6 (Fig. 2). The FOPT was introduced through the tube to the tip of the tube via a specially constructed connector. The balloon was inflated to $60-80 \mathrm{~cm} \mathrm{H}_{2} \mathrm{O}$ and burst with a flame. Pressure signals were sampled at $3 \mathrm{kHz}$.

Influence of the FOPT on ETT resistance during constant flow in inspiratory and expiratory directions. Pressure-flow relationships were studied in a system of respiratory tubing, a pressure transducer (proximal pressure), a connector for the introduction of the FOPT into the ETT of neonatal or pediatric dimensions $(3,4,5$, and $6 \mathrm{~mm} \mathrm{ID)}$, a 
model of a neonatal or pediatric trachea, and a pressure transducer for measuring tracheal pressure (Fig. 3). ETT 3 and $4 \mathrm{~mm}$ ID were flushed with air in inspiratory or expiratory direction at flows of $1,2,3,4$, or $5 \mathrm{~L} / \mathrm{min}$, and ETT 5 and $6 \mathrm{~mm}$ ID were flushed at flows of 2, 4, 6, 8, and 10 $\mathrm{L} / \mathrm{min}$. The flows are considered representative of clinical flows. Flow was measured at the outlet with a flowmeter (Timeter Instrument Corporation, Oregon Pike, Lancaster, PA U.S.A.). Pressure reduction was calculated and displayed as a function of flow. Dimensions of ETT and model tracheas are shown in Table 1.

Comparison of measured and calculated pressure fall across the tube. As all flows were below the critical Reynolds' number, they were laminar. Thus for calculation of pressure drop the Ito equation was applied and compared with pressure drop measurements using a standard pressure transducer for proximal pressure and the FOPT for the tracheal pressure.

Influence of the FOPT on ETT resistance during dynamic conditions in a lung model. A Servo 900C (Siemens Elema, Solna, Sweden) was connected with pediatric tubing to ETTs 3, 4, 5, or $6 \mathrm{~mm}$ ID, a model trachea of length and diameter according to Table 1, and a pediatric lung model (Fig. 4). The system was ventilated with air at a frequency of 40/min and inspiratory-to-expiratory ratios of $1: 2,1: 1$, and $2: 1$. Volume was measured with side-stream spirometry incorporated in Datex AS/3 spirometry module. Tracheal pressure was sampled at $25 \mathrm{~Hz}$ at the tip of the tube via the FOPT inserted through the lumen of the ETT, and reference pressure was measured at a side hole in the model trachea via a conventional pressure transducer. $\mathrm{P} / \mathrm{V}$ loops were constructed from FOPT, reference pressure transducer, and volume signal, and the areas of the $\mathrm{P} / \mathrm{V}$ loops were compared. Tracheal pressure was calculated according to Guttmann et al. (2) and compared with actual measured pressure.

Influence of secretion on calculation of tube resistance. The lung model was intubated with an ETT of 2.5, 4, or 5 $\mathrm{mm}$ ID and ventilated in volume-controlled mode (Fig. 4). Xylocaine gel corresponding to $10 \%$ of inner tube volume was deposited mid tube and allowed to disperse during 5-10 breaths. Proximal P/V loops obtained by side-stream spirometry were compared with distal $\mathrm{P} / \mathrm{V}$ loops composed of lateral tracheal pressure and spirometry volume. Inspiratory resistance was calculated as difference between proximal

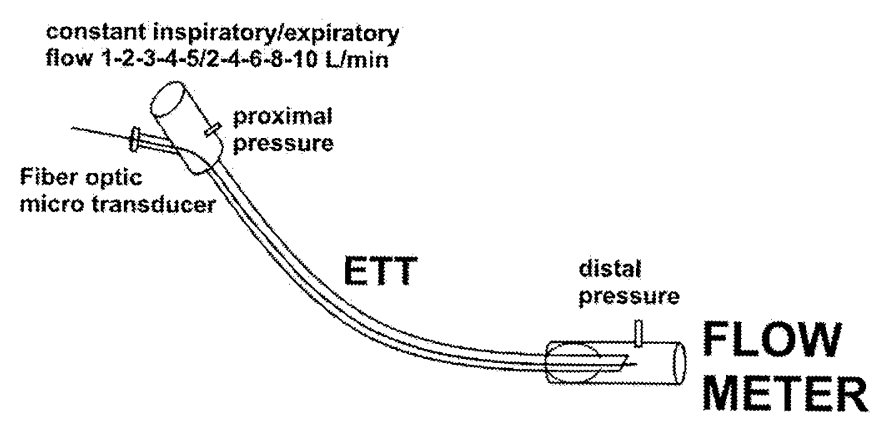

Figure 3. Determination of influence of presence of fiberoptic microsensor on pressure-flow relationship during constant inspiratory or expiratory flow.
Table 1. Combination of dimensions of ETT (ID/OD and length) and model trachea (ID/OD and length) used in tests

\begin{tabular}{cccc}
\hline $\begin{array}{c}\text { Tube, ID/OD } \\
(\mathrm{mm})\end{array}$ & $\begin{array}{c}\text { Tube length, nares } \\
\text { to midtrachea } \\
(\mathrm{cm})\end{array}$ & $\begin{array}{c}\text { Trachea ID/OD } \\
(\mathrm{mm})\end{array}$ & $\begin{array}{c}\text { Distance, glottis } \\
\text { to carina }(\mathrm{cm})\end{array}$ \\
\hline $3 / 4.4$ & 11 & $5 / 9$ & 4 \\
$4 / 5.6$ & 14 & $7 / 9$ & 5 \\
$5 / 6.7$ & 17 & $8 / 12$ & 6 \\
$6 / 7.2$ & 20 & $9 / 12$ & 7 \\
\hline
\end{tabular}

and distal pressure measured by conventional pressure transducers divided by mean value of constant inspiratory flow.

Clinical use of the FOPT. After parental consent and approval of by the Ethics Committee of Göteborg University, pressure measurements were performed in three patients postoperatively ventilated in pressure- and volume-controlled mode with a Servo 300 (Siemens Elema) and in two patients during surgery ventilated with a Servo 900C. Patient data are shown in Table 2.

Measurement periods corresponded to length of operation or a routine 3 -h interval between tube cleansing maneuvers. Ease of positioning, long-term measurement, and interference with clinical examination and nursing was assessed. ETT resistance was calculated.

\section{Statistics and Calculations}

Constant flow. Resistance was calculated as pressure drop (proximal minus tracheal pressure or vice versa depending on flow direction) divided by flow. Regression coefficient and equation was calculated for tracheal pressure versus transducer pressure. Pressure fall calculated according to the Ito formula (7) was compared with measured pressure fall using $t$ test.

Dynamic conditions. Data were analyzed by linear regression between reference tracheal pressure and FOPT.

\section{RESULTS}

Response time. Both the FOPT and the conventional pressure transducer reached 0 pressure in $1.3 \mathrm{~ms}$. In the experimental setup, oscillations were seen amounting to a few per-

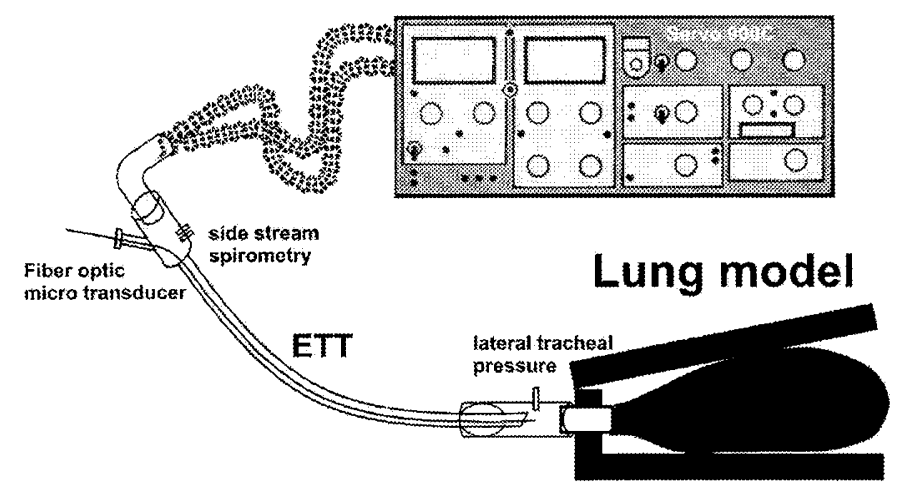

Figure 4. Measurement of correlation of reference tracheal pressure and FOPT in a dynamic lung model. 
Table 2. Patient age, weight, and ETT used for clinical evaluation of FOPT

\begin{tabular}{llcc}
\hline \multicolumn{1}{c}{ Procedure } & Age & Weight $(\mathrm{kg})$ & ETT no. \\
\hline Postoperative cardiac surgery & $1 \mathrm{mo}$ & 5 & 3.5 \\
Postoperative cardiac surgery & $2 \mathrm{wk}$ & 3.5 & 3.0 \\
Postoperative cardiac surgery & $1 \mathrm{mo}$ & 4.5 & 3.5 \\
Orthopedic surgery & $6 \mathrm{mo}$ & 8 & 4.5 \\
Appendectomy & $9 \mathrm{y}$ & 30 & 5 \\
\hline
\end{tabular}

cent of the pressure fall. Most probably these were derived from oscillations in the air column of the system.

Influence of the FOPT on ETT resistance during constant flow. With a diameter of $0.25 \mathrm{~mm}$ of the micropressure transducer the reduction of luminal area amounts to $0.7 \%$ in ETT no. 3, $0.4 \%$ in ETT no. $4,0.25 \%$ in ETT no. 5, and $0.17 \%$ in ETT no. 6 . The pressure-flow relationship was curvilinear for all dimensions and flow rates in both inspiratory and expiratory directions and was fitted to a seconddegree polynomial. The presence of FOPT did not in any case increase the pressure fall significantly across the tube, and $t$ test did not reveal any significant differences between presence versus absence of sensor, or between inspiratory versus expiratory flow direction. Figure 5 illustrates the pressure-flow relationship for four dimensions of ETT up to flow $5 \mathrm{~L} / \mathrm{min}$ (ETT 3 and 4) and $10 \mathrm{~L} / \mathrm{min}$ (ETT 5 and 6).

Comparison of measured and calculated pressure fall across the tube. The pressure drop calculated by the Ito formula varied from 6 to $64 \%$ of the measured pressure drop.

Influence of the FOPT on ETT resistance during dynamic conditions in a lung model. As shown in Table 3 , regression coefficients were close to unity, and equations for three positions of the pressure transducer relative to the tip of ETT showed slopes close to 1.0 and intersections with the $y$ axis less than $0.4 \mathrm{~cm}$. The comparison between the two measurement methods is displayed in a Bland-Altman plot in Figure 6. Proximal and distal peak pressures differed considerably dependent on tube-related inspiratory resistance. The areas of the distal (tracheal) $\mathrm{P} / \mathrm{V}$ curve were 25 to $48 \%$ of the proximal (Y-piece) $\mathrm{P} / \mathrm{V}$ areas (Fig. 7). There were large differences in calculated tracheal and directly measured pressure (Fig. 8).

Effect of secretions on tube resistance. Figure 9 illustrates the effect of introducing artificial secretions amounting to $10 \%$ of inner tube volume into the ETT. Resistance increased from 12 to $37 \mathrm{~cm} \mathrm{H}_{2} \mathrm{O} \cdot \mathrm{s} \cdot \mathrm{L}^{-1}$ in ETT no. 5 with volume controlled ventilation at a constant flow of $13 \mathrm{~L} / \mathrm{min}$ and from 120 to $380 \mathrm{~cm} \mathrm{H}_{2} \mathrm{O} \cdot \mathrm{s} \cdot \mathrm{L}^{-1}$ in ETT no. 2.5 at constant flow of $6 \mathrm{~L} / \mathrm{min}$.

Micropressure transducer in pediatric intensive care unit patients. The length of connector and tube was measured in advance and marked on the optical micropressure transducer. This was easily introduced into the pediatric tube by way of a polyethylene catheter, which was retracted to a position outside the connector, when the transducer was in place at the tip of the ETT. If the FOPT protruded beyond the tip of the tube, it had a tendency to stick in the tracheal mucosa. Its function was undisturbed by routine nursing procedures such as wound dressing and positioning for radiography. The proximal pressure profile in volume- and pressure-controlled ventilation differs with respect to rise time as step increase versus linear increase. This difference is not transmitted through the ETT. The optic fiber sensor showed a tendency to zero drifting, which was easily corrected in acquisition software as PEEP pressure at zero flow was present in ventilator or spirometry tracings between tidal breaths. Figure 10 illustrates the clinical calculation of tube resistance during volume-controlled ventilation.
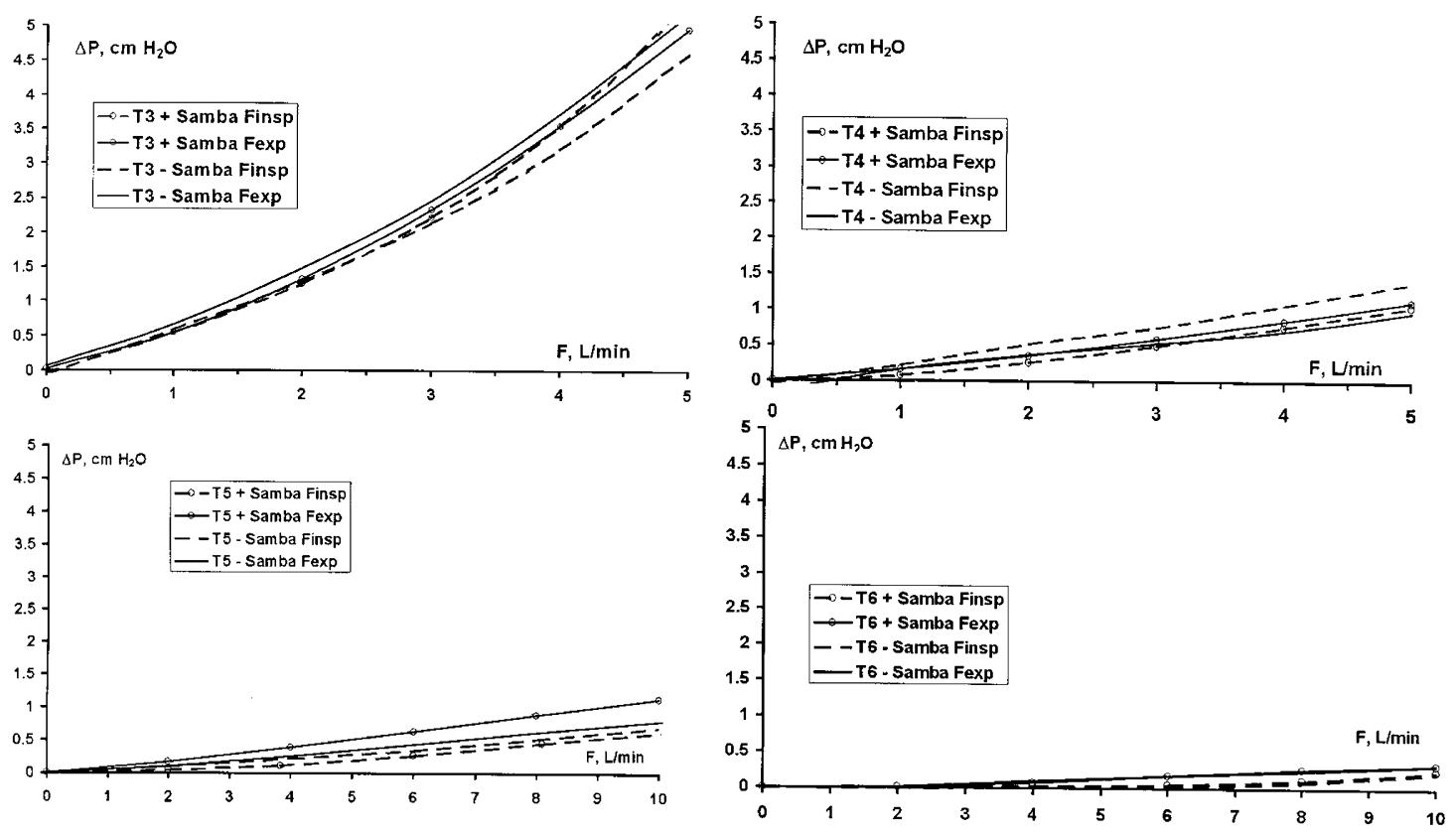

Figure 5. Pressure-flow relationship with constant inspiratory (Finsp; stippled) and expiratory (Fexp; solid) flow in ETT 3, 4, 5, 6 with (circles) or without FOPT in lumen. The pressure drop across the tube was not affected (NS) by the insertion of the micropressure transducer. 
Table 3. FOPT versus reference tracheal pressure (conventional pressure transducer) during dynamic conditions in a lung model

\begin{tabular}{|c|c|c|c|c|}
\hline Position of FOPT & $R^{2}$ & $\alpha$ & $\begin{array}{c}\mathrm{Y}_{0} \\
\text { (cm H} \mathrm{H}_{2} \mathrm{O} \text { ) }\end{array}$ & $\begin{array}{c}\mathrm{RMS} \\
\left(\mathrm{cm} \mathrm{H} \mathrm{H}_{2} \mathrm{O}\right)\end{array}$ \\
\hline$-1.5 \mathrm{~cm}$ & $0.987 \pm 0.003$ & $0.996 \pm 0.04$ & $0.326 \pm 0.36$ & 0.865 \\
\hline at tip & $0.998 \pm 0.001$ & $0.976 \pm 0.02$ & $0.394 \pm 0.36$ & 0.650 \\
\hline$+1.5 \mathrm{~cm}$ & $0.999 \pm 0.001$ & $0.986 \pm 0.02$ & $0.151 \pm 0.27$ & 0.627 \\
\hline
\end{tabular}

Inspiratory to expiratory ratio was $1: 2,1: 1$, or $2: 1$; PEEP was 0 or $10 \mathrm{~cm}$ $\mathrm{H}_{2} \mathrm{O}$. Regression equation is $\mathrm{P}_{\mathrm{FOPT}}=\alpha \times \mathrm{P}_{\mathrm{TR}}+\mathrm{Y}_{0}$. Results are given as mean $\pm \mathrm{SD}$ and root mean square (RMS).

$\mathrm{P}_{\mathrm{FOPT}}$, pressure measured by FOPT; $\mathrm{P}_{\mathrm{TR}}$, tracheal pressure measured by conventional pressure transducer.

\section{DISCUSSION}

We have presented data concerning the use of a smalldiameter optic fiber with a microtransducer at its tip for tracheal pressure measurement in ventilator-treated pediatric and neonatal patients. Measurements are obtained by introducing the FOPT through the ETT lumen. Our results show that its response time is extremely short and that its presence in the ETT lumen has minimal influence on ETT resistance as the encroachment on luminal area is negligible. We have also shown that the position of the FOPT in relation to the tip of the tube, $-1.5 \mathrm{~cm}, 0$, or $+1.5 \mathrm{~cm}$, does not have any greater influence on measurement compared with a reference pressure measured in a lung model, but for practical reasons the FOPT should be kept inside the ETT.

The clinical application of the FOPT proved easy and tolerant to nursing procedures. Measurement periods were restricted to a 3-h interval between routine suctioning to keep the tube open, but as shown, the presence of a tracheal pressure measurement makes it possible to monitor actual changes in tube resistance. It is noteworthy that calculated pressure fall in the clinical setting is different from the test bench measurement at identical flow and tube size. This finding is in agreement with results comparing in vitro and in vivo ETT resistance (12, 13).

De Blasi et al. (14) in 1992 presented a fiberoptic technique for tracheal pressure measurement, the Camino XP400, with good results. However, its diameter of $1 \mathrm{~mm}$ was far too coarse to be inserted into a neonatal ETT, and to our knowledge tracheal pressure measurement with smalldiameter sensors has not since been attempted. The fiberoptic method of direct measurement is an alternative to earlier attempts to obtain tracheal pressure by calculation, i.e. indirect methodology, based on pressure measurements proximal to the ETT and pressure-flow relationships defined in bench test. Jarreau and coworkers (4) have presented a very comprehensive study of calculation of the pressure drop based on pressure and flow measured above the tube combined with the Ito equation for the pressure-flow relationship across the tube and a factor for the kinetic energy loss across different connectors. They found that the pressure drop across the tube was 13 to $37 \%$ of the total pressure fall across the tube and connector together, and they also found a very good agreement between calculated and measured pressure drop. In contrast to Jarreau et al. (4), we found that the pressure fall across the tube made up between
6 and $64 \%$ of the total pressure drop. This may be ascribed to the difference in connectors used. Guttmann et al. (2) presented another approach to the problem using, in a single smooth-walled tube, the Rohrer (15) polynomial equation, which originally was derived for the calculation of pressure drop in multiply branching systems like the human airway. However, several other groups $(12,13)$ have described difficulties in obtaining correct tracheal pressure level by indirect methodologies. The reasons for this are most probably that there are too many factors differing between the bench test and the clinical situation. Connectors, heatmoisture exchangers, tube length, and tube kinking and compression during passage of nasal cavity may seriously alter the resistance of the ETT. Thus, the ideal conditions of bench tests including measuring apparatus will seldom be found and used bedside. Also, the presence of secretions, in which amounts of secretions of as little as $10 \%$ of the tube volume dispersed on the interior surface (corresponding to a

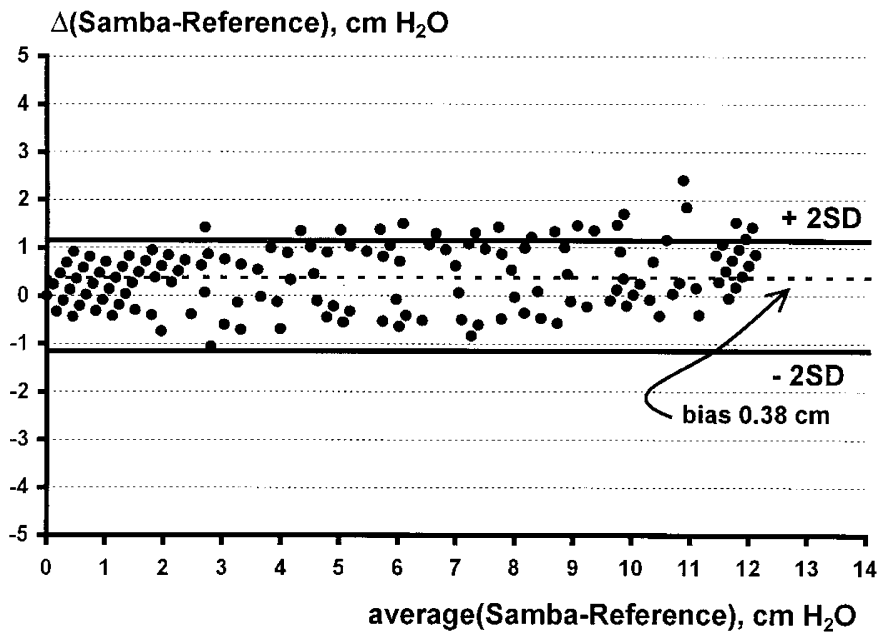

Figure 6. Bland-Altman plot of micropressure transducer at tip $v s$ reference pressure in tracheal model, ETT no. 3. Bias of $0.38 \mathrm{~cm} \mathrm{H}_{2} \mathrm{O}$ and $\pm 2 \mathrm{SD}$ are indicated.

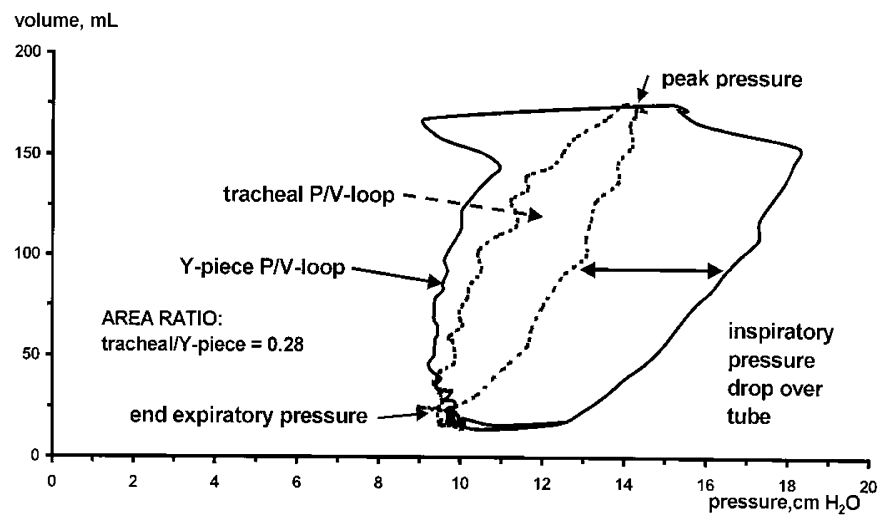

Figure 7. Volume-controlled ventilation with ETT no. 5. Distal P/V loop composed of microtransducer pressure and spirometry volume. Note that the tracheal loop is completely concealed within the Y-piece loop and there is no possibility of knowing true peak pressure nor PEEP level from the Y-piece loop. 


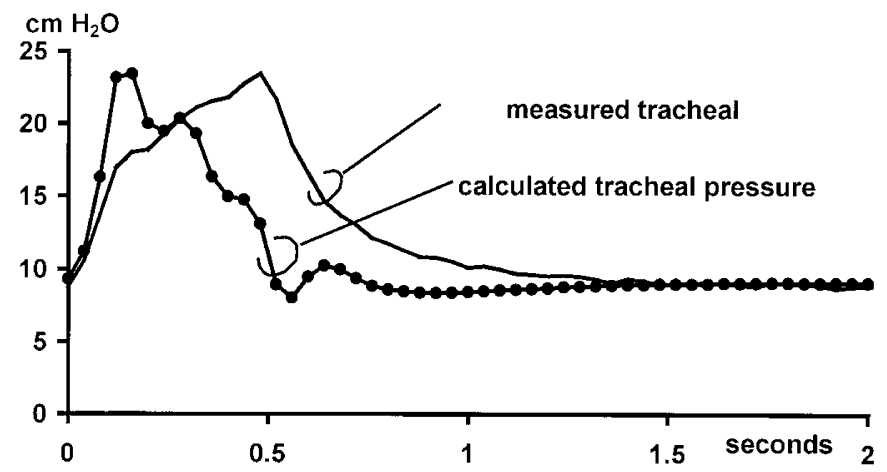

Figure 8. Tracheal pressure measured by FOPT and calculated tracheal pressure ad modum. Guttmann during pressure-controlled ventilation at PEEP $8 \mathrm{~cm} \mathrm{H}_{2} \mathrm{O}$ in ETT no. 3.

decrease in diameter of a $5-\mathrm{mm}$ tube to $4.75 \mathrm{~mm}$ ) results in three times increase in tube resistance. This may be an explanation of why we, in a patient (Fig. 8), could see little resemblance between calculated and directly measured tracheal pressure. Kárason et al. (1) experimentally demonstrated that secretions made calculations according to mathematical modeling of tracheal pressure very precarious in adult tubes. In this study we found the same type of differences between calculated and measured tracheal pressure, which indicates that there are good reasons for using direct tracheal pressure measurements. Figure 7 further emphasizes this: proximal and tracheal peak pressure differ by 4 $\mathrm{cm}$ dependent on tube characteristics (length, curvature, secretions, compression) not easily recognized in the clinical situation and impossible to account for mathematically. The direct measurement of tracheal pressure may thus represent a better measurement for the monitoring of respiratory pressures.

Our clinical experience using the micropressure transducer is preliminary, but a few points are worth mentioning. The proximal pressure profile in volume- and pressurecontrolled ventilation differs with respect to rise time. This difference is not transmitted through the ETT. In adult respiratory care pressure-controlled ventilation is often applied owing to faster displacement of tidal volume, lower peak pressure, and higher mean airway pressure with consequent improved oxygenation. The small diameter and large resistance of the pediatric tube may attenuate the benefit of changing ventilation mode. The pressure measurement proximally and distally allows for the continuous calculation and trending of tube resistance. This may conveniently be incorporated into a monitoring algorithm and used as an early warning of imminent tube obstruction in pediatric patients.

In conclusion, the FOPT represents a novel technology well suited for monitoring of tracheal pressure in neonatal and pediatric ETT dimensions. The optic fiber is thin enough not to create an increased tube resistance. It is easy to handle and gives correct tracheal pressure readings unhampered by kinking, compression, or secretions in the tube.
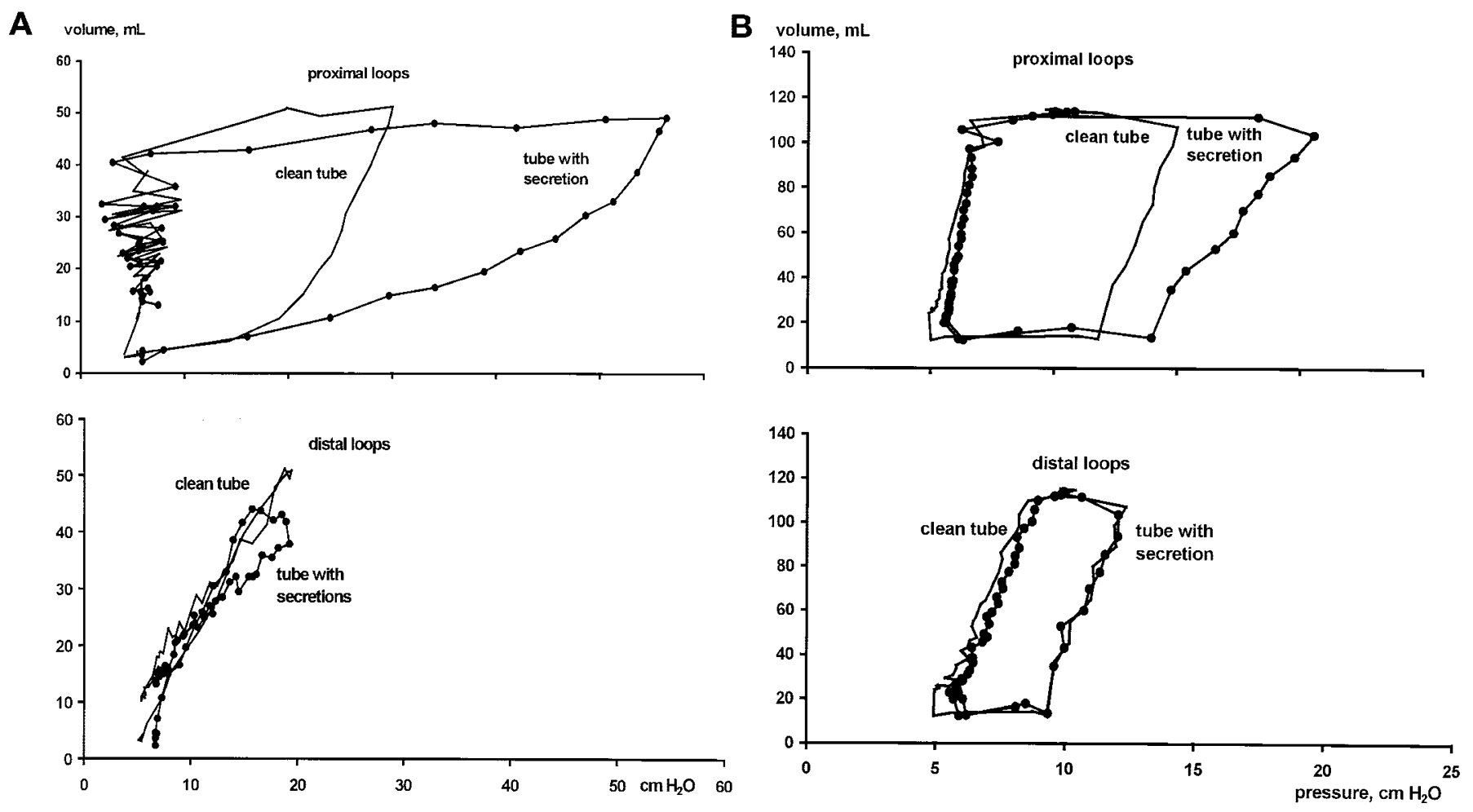

Figure 9. Distal P/V loop (FOPT) vs proximal P/V loop during volume-controlled ventilation using tube no. $2.5(A)$ and tube 5 (B). Upper panels, clean vs obstructed tube corresponding to $10 \%$ of ETT inner volume (circles) in proximal P/V. Lower panels, distal P/V loops from the same measurement. Inspiratory resistance increased from 120 to $380 \mathrm{~cm} \mathrm{H} \mathrm{H}_{2} \mathrm{O} \cdot \mathrm{s} \cdot \mathrm{L}^{-1}$ in ETT no. 2.5 and from 12 to $37 \mathrm{~cm} \mathrm{H}_{2} \mathrm{O} \cdot \mathrm{s} \cdot \mathrm{L}^{-1}$ in ETT no. 5. Note that proximal loops are widened because of secretions, and distal loops are practically identical. 


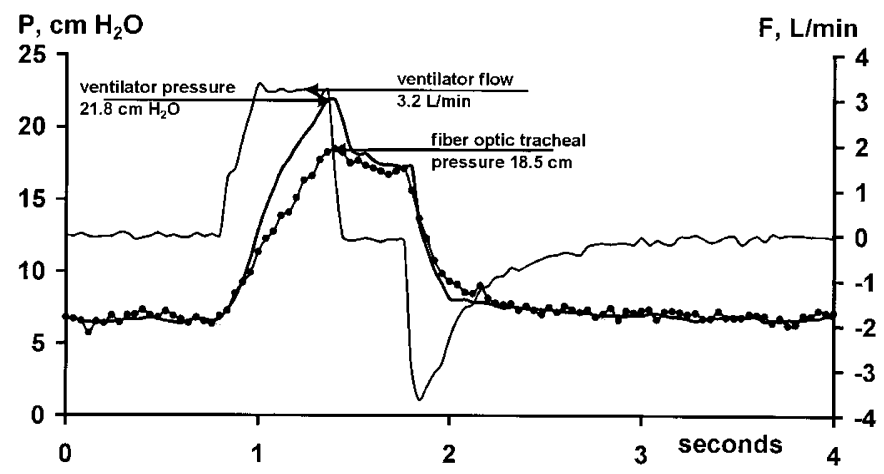

Figure 10. Tracheal pressure from FOPT, flow and proximal pressure from the Servo 300 during volume-controlled ventilation using an ETT $3 \mathrm{~mm}$ ID. Tube resistance was calculated as difference between end-inspiratory pressure measured above and below the tube divided by inspiratory flow: $[(21.8-18.5) \times 60 / 3.2]$ in centimeters of water per liter per second. Note that in this clinical situation the tube resistance differs from the test bench measurements $\left(62\right.$ vs $\left.32 \mathrm{~cm} \mathrm{H}_{2} \mathrm{O} \cdot \mathrm{s} \cdot \mathrm{L}^{-1}\right)$.

Acknowledgment. The Samba monitor was put at our disposal by Datex-Ohmeda, Ltd, and fiberoptic pressure transducers were provided by Samba, Ltd.

\section{REFERENCES}

1. Kárason S, Sondergaard S, Lundin S, Wiklund J, Stenqvist O 2000 Evaluation of pressure/volume loops based on intratracheal pressure measurements during dynamic conditions. Acta Anaesthesiol Scand 44:571-577
2. Guttmann J, Kessler V, Mols G, Hentschel R, Haberthur C, Geiger K 2000 Continuous calculation of intratracheal pressure in the presence of pediatric endotracheal tubes. Crit Care Med 28:1018-1026

3. Guttmann J, Eberhard L, Fabry B, Bertschmann W, Wolff G 1993 Continuous calculation of intratracheal pressure in tracheally intubated patients. Anesthesiology 79:503-513

4. Jarreau PH, Louis B, Dassieu G, Desfrere L, Blanchard PW, Moriette G, Isabey D, Harf A 1999 Estimation of inspiratory pressure drop in neonatal and pediatric endotracheal tubes. J Appl Physiol 87:36-46

5. Pedley JP, Kamm RD 1991 Dynamics of gas flow and pressure-flow relationships. In: Crystal RG, West JB (eds) The Lung: Scientific Foundations. Raven Press, New York, pp 995-1010

6. Ito H 1959 Friction factor for turbulent flow in curved pipes. J Basic Eng $81: 123-134$

7. Ito H 1969 Laminar flow in curved pipes. Z Angew Math Mech 49:653-663

8. Lofaso F, Louis B, Brochard L, Harf A, Isabey D 1992 Use of the Blasius resistance formula to estimate the effective diameter of endotracheal tubes. Am Rev Respir Dis 146:974-979

9. Loring SH, Elliott EA, Drazen JM 1979 Kinetic energy loss and convective acceleration in respiratory resistance measurements. Lung 156:33-42

10. Sly PD, Lanteri CJ, Nicoloai T 1996 Measurement of respiratory function in the intensive care unit. In: Stocks J, Sly PD, Tepper RS, Morgan JW (eds) Infant Respiratory Function Testing. Wiley-Liss, New York, pp 445-484

11. Xiao Z 1996 Applications of artificial microcavities in wafer bonded silicon. Technical Report No. 285 Department of Solid State Electronics, Chalmers University of Technology, Gothenburg, pp 1-41+5 papers

12. Wright PE, Marini JJ, Bernard GR 1989 In vitro versus in vivo comparison of endotracheal tube airflow resistance. Am Rev Respir Dis 140:10-16

13. Warters RD, Allen SJ, Tonnesen AS 1997 Intratracheal pressure monitoring during synchronized intermittent mandatory ventilation and pressure controlled-inverse ratio ventilation. Crit Care Med 25:227-230

14. De Blasi RA, Conti G, Antonelli M, Bufi M, Gasparetto A 1992 A fibre optics system for the evaluation of airway pressure in mechanically ventilated patients. Intensive Care Med 18:405-409

15. Rohrer F 1915 Der Strömungswiderstand in den menschlichen Atemwegen unter der Einflu $\beta$ unregelmässigen Verzweigung des Bronchialsystems auf den Atmungsverlauf in verschiedenen Lungenbezirken. Pfluegers Arch Ges Physiol $162: 225-259$ 